\title{
Turnover Intentions, Training, and Motivations among Australian Union Staff ${ }^{1}$ \\ Nick Brander-Peetz, David Peetz \& Paula Brough ${ }^{2}$
}

\begin{abstract}
Staff loss and demotivation can be costly for unions. We investigated factors influencing intentions to leave (ITL) of union employees by conducting an online survey of 160 staff in three Australian unions. Employees reported strong intrinsic and pro-social motivations. Moderated multiple regression analyses revealed that organisational support, shortcomings in training and unmet intrinsic needs predicted ITL, after controlling for burnout and labour market mobility. Critically, the results suggest an interaction effect involving training in some circumstances. Training buffered the impact of low support on ITL, however the adverse effect on ITL of organisational failure to meet staff expectations regarding service to members appeared to exist independently of training. Implications for theory and practice are discussed, including the separate significance of resources and purpose.
\end{abstract}

1 This is a pre-print of the article published as Nick Brander-Peetz, David Peetz \& Paula Brough, 'Turnover Intentions, Training, and Motivations among Australian Union Staff', Economic and Industrial Democracy, 2021. DOI: 10.1177/0143831X211017216. The text differs slightly from the published version. For the definitive text, see the published version.

2 Griffith University, Brisbane, Australia. 


\section{Turnover intentions, training, and motivations among Australian union staff}

In the face of declining membership density, Australian unions have sought to effect major changes to their internal structures and operations. In the late 1990 s and early 2000 s substantial impetus was given by two reports from the Australian Council of Trade Unions (Cooper, 2003) which signalled changes including: reallocating resources from industrial work to organising; undertaking extensive training and education of workplace delegates; requiring organisers to follow-up with delegates regarding the application of lessons from their on-the-job training; and internal restructuring to separate 'member service' and functional organising. Since then, divisions and branches have been created, abolished and amalgamated; power has been transferred from union officials to workplace unionists or delegates; and staff with outdated skills have been redeployed, retrained or made redundant and replaced with new recruits.

These changes placed new and heavier demands on staff. Declining resources and membership numbers meant that staffing was reduced, and unions sought to 'do more with less'. The imposition of new tasks without additional resources created pressure upon employees, and increased stress led to increased staff turnover (Carter and Cooper, 2002). Some unions introduced performance management procedures, both formal and informal. These strategies demonstrated that staff performance was crucial, and if staff left after a short period or become quickly demotivated, the union may have wasted a major investment in human resources. Accordingly, we ask what motivates union staff and determines their Intentions to Leave (ITL)? This article reviews the literature on union employees and summarises key issues relating to turnover and motivations, including expectations, training and support. 


\section{Background}

\section{Research on union employees}

Substantial research has been directed towards the declining membership density of trade unions both internationally and in Australia. Along with corresponding outcomes such as a reduction in political-industrial power, remedies to address these systematic concerns and bolster union effectiveness have been widely discussed (Muir and Peetz, 2010). While numerous union studies reference organisational design, leadership, and other theories relevant to predicting workplace and membership satisfaction (e.g. Kgapola, 2017), these studies mainly focus on members rather than union employees. Some scholars have investigated the impact of union employee characteristics on union effectiveness, including the role of member-orientation (Gahan and Bell, 1999), and workplace delegate relationships (Markey and Simpkin, 2017). Yu (2018) examined union staff ideals and their impact on organisational inclusivity, role boundaries and career development, however this was a qualitative exploration in the United States and did not quantify any theorised relationships. Within an Australian context, Burchielli (2004) also used a qualitative methodology to explore union employees' opinions and developed a theoretical model of effectiveness that included ideology as a central pillar. Few studies have reached beyond these broad overviews of collective values or political affiliation - as typically linked to union members - to isolate specific motivational drivers of union staff. Scant research on union effectiveness has explored the role of employee characteristics in contributing to organisational performance, with quantitative methodologies rarely used.

Researchers have applied organisational theories to trade unions to assess their behaviour (e.g. Gall and Fiorito, 2014). In the US, Clark and Gray (2007) found unions were formalising human resource policies, strategic planning, and systematic financial practices 
in reaction to changes in operating environments and declining resources. Longitudinal reviews reaffirmed these trends, observing that unions have increasingly adopted budgeting practices, taken on external consultants for advice, and implemented formal performance assessments (Whitehead et al., 2018). These studies lack detail on specific mechanisms underlying employee processes relating to recruitment, motivation and turnover. Such processes are important as some unions demand great commitment from staff while ignoring the emotional toll (McAlevey and Ostertag, 2014) or failing to provide adequate training, resulting in frustration (Milkman and Voss, 2004).

Historically, scholars have had limited access to unions when it comes to evaluating employee motivations and employee attitudes towards control-oriented HR policies. To the authors' knowledge, this article represents the first quantitative study on a comprehensive range of motivational drivers of union employees.

\section{Turnover intentions}

High turnover can be expensive, with the costs associated with individual turnover estimated to range between $50 \%$ and $150 \%$ of annual salary (VPSC, 2015) depending on role complexity and other factors. Turnover costs may be tangible (e.g., managerial time spent on interviews) or intangible (e.g., missing skills and expertise), resulting in hidden losses (Allen et al., 2010). For staff left behind, turnover may weaken morale and networks, while increasing cynicism and workload (Byrnes and Lawn, 2013). Turnover of union employees may increase anxiety in members or harm the confidence of workplace delegates if their networks are disrupted, especially if a new employee is less competent (Hom et al., 2019).

ITL, defined by an 'individual's estimated probability that they will leave the organisation at some point in the near future' (Brough and Frame, 2004: 8), is directly 
linked to immediate turnover behaviour (Tett and Meyer, 1993). For instance, Allen et al's (2010) meta-analysis found that ITL and job search were the two strongest predictors of actual turnover behaviour (Allen et al., 2010).

Even in a labour market with poor mobility, where employees may want to leave but feel compelled to stay due to constrained choices (Li et al., 2016), ITL is important to measure because it reflects passive withdrawal and unproductive behaviours (Chang et al., 2013), negative attitudes (Felps et al., 2006), absenteeism (Hanisch, 2002) and lowered productivity (Li et al., 2016), leaving employers vulnerable to passive aggression and critical gaps in knowledge (Tangirala and Ramanujam, 2008). If employees lower their voice due to fear of losing their job or feelings of futility in an drawn-out crisis, new organisational norms of silent dissent and information withholding may emerge (Prouska and Psychogios, 2018).

\section{Turnover in unions}

A study of 379 Australian organizers from 13 unions (Peetz et al., 2005) found low ITL (80\% expected to be still working for the union in two years) and high job satisfaction (83\% were satisfied with their job). While many agreed that their workload was excessive, ITL was not significantly associated with workload, but instead was related to frustration with a difficult job that lacked effective support and where members' influence was weak. In short, ITL was more strongly linked to factors reflecting the ability of the union to help its members, rather than to the burden of their employees' workload (Peetz et al., 2005). ITL may not just be an indicator of staff dissatisfaction, they may also be a proxy of poor union performance. When considered within the literature on psychological contract and personenvironment fit (Cooper - Thomas and Wright, 2013), these results suggest that intrinsic 
motivations to serve the membership and community, and the fulfilment of related expectations, could be central to ITL in the union population.

\section{Motivations at work}

A voluntary decision to leave a union job can be seen as a loss of that employee's motivation to work for that employer - at least, relative to realistic alternatives. This makes the study of motivation relevant to understanding ITL. Traditional models of work motivation in non-corporate settings were challenged when Perry and Wise (1990) formulated public service motivation (PSM) theory, arguing that public sector workers were driven to contribute to society and help others, often at the expense of their own interests. Studies of PSM quickly expanded, notably due to its potential for informing how employees may work energetically despite uncompetitive remuneration (Vandenabeele et al., 2014). Values-based recruitment, whereby candidates are selected based on their attitudes and principles, has become the standard framework for talent assessment in many human service organisations (Patterson et al., 2016), with authors arguing that performance can be improved by using PSM as selection criteria (Brewer, 2008) and by fostering PSM through socialization and job design (Moynihan, 2010). PSM has been further advanced for its ability to mitigate the risk of exhaustion (Bakker, 2015) and corruption (Kwon, 2012).

However, using PSM in this way has the potential for a mismatch between the ideals of PSM and the realities of work (Vandenabeele et al., 2014). Employees can become frustrated by government controls, internal red tape, excessive workload, difficult clients, or a lack of recognition (Giauque et al., 2013). Self-sacrifice can negatively affect wellbeing, absenteeism and presenteeism as employees overreach their own resources (Jensen et al., 2019). Some argue PSM still lacks a clear conceptual framework (Schott et al., 2019) or is based on a false dichotomy (Ritz et al., 2016a). In a review of 323 publications on PSM, Ritz 
and colleagues (2016) concluded that most researchers misrepresent PSM as a purely altruistic concept. Individuals may perform public service for self-interested or instrumental reasons (Perry, Hondeghem, \& Wise, 2010), and few empirical PSM articles incorporate drivers such as work-life balance, job security, social status, and advancement (Perry, 2014). The debate on extrinsic and intrinsic drives is also relevant. Various scholars claim that external mechanisms, such as monetary rewards, can 'crowd out' intrinsic motivations (Frey and Jegen, 2001). Others suggest overall motivation (the combined input of intrinsic and extrinsic rewards) is most important for work outcomes (Coccia, 2019). To help resolve some of these puzzles, this paper surveys a union sample and investigates: how individual factors and working conditions interact across roles, industries and situations; how employee burnout affects ITL in high-PSM individuals; and how extrinsic factors drive commitment beyond intrinsic meaning.

\section{Motivations and Burnout of Union Employees}

What is known about the characteristics and motivations of union employees? Recent studies indicate an increasing interest in social justice (Yu, 2018), in addition to a long-standing interest in workplace justice, as suggested by qualitative interviews with union administrators (Burchielli, 2008) and books on union officers (Kelly and Heery, 2009) among other sources. Through interviews with union staff, Burchielli (2004) explored a range of ideological pillars underlying union effectiveness, suggesting that union employees tend to be driven by more than pro-social motivations to serve members, whereby their intensity of belief in righteous equality, fairness, and opportunity transforms into a staunch desire for social-industrial justice and political change. They seek to achieve this through group action and values of social connectedness, and aim to activate membership through spreading their beliefs and encouraging independent organising (Burchielli, 2004). Staff 
seem to expect great workplace commitment, organised militancy and ideological purity for themselves and fellow officials (Burchielli, 2004).

Another Australian survey of 379 union organisers showed that $73 \%$ had worked in the same industry as their membership and $36 \%$ had campaigned for a political party (Peetz et al., 2005). In that same sample, the median number of hours worked per week was 48 , with $22 \%$ working over 55 hours per week. These characteristics are suggestive of strong occupational affiliation, shared identity and emotional investment in their members, along with strong dedication to their work. As union employees identify with the members and their hardship, they are more likely to be intrinsically motivated to serve their members (Yu, 2018). Identification with their members might reflect their job role, shared vocational experience and struggle, similarity in beliefs and attitudes (Martin, 1999), or even perceived injustice in early life (Yu, 2018).

Their keen interest in work-related justice $(Y u, 2018)$ means they are more likely to be aware and critical of management policies and practices. This could increase pressure on union management to ensure all organisational ideals are put into practice internally (Thompson and Bunderson, 2003). Indeed, there is an established literature linking perceptions of organisational justice with ITL (Siers, 2007). Perhaps more importantly, union employees may be motivated by the good they see the union as doing, and their desire to stay with it may depend on whether the union continues to achieve that.

There is a strong causal link between burnout and turnover in human service employees such as teachers (Lee, 2019), with a higher risk of burnout among employees that work during evening hours and lack psychological detachment from their job (Sonnentag and Bayer, 2005). Timms et al. (2012) found that employee burnout, while generally linked to low engagement (vigour, dedication, absorption) at work, did not 
necessarily lead to low engagement - and by implication to ITL. Related evidence for the role of PSM in reducing exhaustion due to high work demands (Bakker, 2015) suggests that some union employees may feel 'burned out but engaged'. Employees with high PSM are at risk of over-reaching themselves due to intra- or inter-personal moral obligations (van Loon et al., 2015), social pressure, or organisational commitment. Those with a strong calling tend to make sacrifices and work long hours, and seem to expect the same from their peers (Bunderson and Thompson, 2009). Union employees may thus feel compelled to work later and acquiesce to decisions for political or practical reasons, culminating in passive aggression and burnout.

In short, individuals appear to be commonly drawn to work in unions based on a sense of intrinsic motivation, common identity, and interests in industrial-social justice and political change. They seem characterised by a militancy of beliefs regarding ideology and workplace commitment, which may lead to burnout in some cases. Union work has a specific context, and this context is likely to influence PSM-work relationships (Christensen et al., 2017). Therefore, union employees may behave differently to others when it comes to ITL. Building on the above literature, we hypothesize:

$H_{1}$ : Intrinsic motivations (value alignment, membership orientation, pro-social motivation, and enjoyment) of union employees will be negatively associated with ITL.

$\mathrm{H}_{2}$ : Extrinsic motivations (social approval, finances, job security, and advancement) of union employees will be negatively associated with ITL, but not as strongly as intrinsic motivations.

In addition, given our brief discussion of the burnout literature, along with the likely importance of union managers ensuring that all organisational ideals are put into practice internally, we hypothesis that: 
$H_{3}$ : Burnout among union employees will be positively associated with ITL.

$H_{4}$ : Perceived organisational support by the union for union employees will be negatively associated with ITL.

\section{Expectations of membership service}

While a few unions continue growing amidst difficult economic conditions, such as nursing unions (ANMF, 2019), union power has been in general decline across the West for several decades (Gall and Fiorito, 2016; Crouch, 2017). One organisational risk associated with declining bargaining power relates to its effect on employee expectations regarding their own ability to make an impact and regarding their union's power more broadly. A study of public servants found that the fulfilment of expectations was linked to organisational commitment (Castaing, 2006), and in unions there is already evidence that, when union leaders' ideals for social reform were not actioned by their union, they quit (Ganz et al., 2001). Other aspects of work such as red tape (Giauque et al., 2012) and a lack of training might also reduce the perceived potential social impact of the work, thus decreasing satisfaction while increasing stress and ultimately, ITL.

The 'psychological contract' (French et al., 1982) has been used to conceptualise employees' subjective beliefs regarding mutual obligations between staff and employer (Conway and Briner, 2005), whereby 'breach' occurs when an employee perceives that promises have been broken (Zhao et al., 2007). In person-environment fit (PEF) theory (French et al., 1982), the more incongruence an employee feels with their work environment, the more stress they experience - and when personal needs cannot be met, ITL increases (Morrow and Brough, 2019). Moynihan and Pandey (2008) found that personorganization fit (the match between employees' own values and those of the organisation) predicted the likelihood employees would stay for the long term. In the context of PSM 
theory then, what is relevant is the congruence between intrinsic motivations of workers and PSM-related characteristics of the work environment (Giauque et al., 2012), rather than the presence of high PSM alone.

While values-based recruitment models recommended choosing a candidate with the right 'fit' (Groothuizen et al., 2018), there seems to be insufficient emphasis on how ITL are influenced when the organisation fails to live up successful candidates' expectations over the course of their tenure. We thus hypothesize:

$H_{5}$ : Unmet expectations of employees regarding their ability to benefit union members will be positively associated with ITL among union employees.

\section{Training and support}

Training builds up the resources available to employees to do their job well. One of the few quantitative studies on attitudes of union staff found that insufficient training and unclear vision from the leadership increased ITL (Peetz et al., 2005). This study found that over $90 \%$ of organisers had received some training, but the quantity of training explained little in the way of other outcomes (Peetz et al., 2005). Only half of organisers were satisfied with their training, with these satisfied organisers more likely to report increased numbers of workplaces with delegates, member influence, and fewer members leaving. Overall, the study indicated that the quality of organiser training appeared important for the organiser-delegate relationship (Peetz and Alexander, 2011). Other studies found that administrative staff lacked training that limited both member service and expansion of their constrained job roles (Burchielli, 2008). These matters are critical to union growth, and likewise for internal retention, yet unions may be compelled to prioritise allocating resources to survival and growth at the expense of programs for training and development (Yu, 2018). 
Training and development programs, to the extent that they foster concrete competence, have been linked to reduced ITL (Haivas et al., 2013) as mediated through processes such as: increasing psychological empowerment (Kang, 2012); linking personal capabilities to career development (Hemdi and Nasurdin, 2006); and increasing commitment due to perceptions of organisational investment in the employee (Chang et al., 2013). It has been proposed that training can help overcome stressors such as burnout and a lack of organisational fairness through fulfilling other needs such as a sense of mastery, achievement (Chang et al., 2013) and job security (Urbanaviciute et al., 2018). If training enables union employees to better meet the needs of members, it may foster greater congruence between employees' values and their job role. It may also bring out competencies that may otherwise be latent. One study of union delegates found an interaction between training, activism and prior community experience, whereby former community activists were more active as union delegates - compared to those without an activist background - only if they had received union training (Peetz and Pocock, 2007). This raises the serious possibility of an interaction effect involving training of union employees and ITL, especially in light of another study that found ITL was influenced by an interaction between perceived employability and social support (De Cuyper et al., 2011), two key variables related to training and development. We thus hypothesise:

$H_{6}$ : Inadequate training of union employees will be positively associated with ITL $H_{7}$ : The relationship between organisational support and ITL among union employees will be moderated by training inadequacies, whereby a lack of organisational support will have a greater, positive association with ITL when training is inadequate. 
$H_{8}:$ The relationship between satisfied member service expectations and ITL among union employees will be moderated by training inadequacies, whereby unmet expectations will have a greater, positive association with ITL when training is inadequate.

Some of the hypotheses we test focus on whether patterns that appear to exist in other groups also apply to union employees with a high sense of PSM. Others investigate new ideas about the role of training and development, and use union employees to test them.

\section{Method}

\section{Participants}

The sample consisted of employees from three white collar Australian unions. Confidential emails linking to an online survey were distributed to 271 employees on behalf of the organizations' secretary. A total of 160 surveys were returned, resulting in a response rate of 59\%. Respondent ages ranged from 18 to 70 years ( $M$ 45.31, SD 11.51). Most of the respondents were female (85\%) and employed fulltime (70\%), with $21 \%$ employed part-time, $5 \%$ temporarily, and $4 \%$ on secondment, contract or casual.

Most employees had completed higher education; qualifications reported were postgraduate (14\%), bachelor (41\%), diploma (29\%), and high school or lower (12\%). Before working for the union, $29 \%$ worked in a field related to their membership, $19 \%$ in politics or volunteered as an activist, $6 \%$ at another union, and $10 \%$ combined in law, finance, human resources or industrial relations. Average tenure in the union movement $=14.32$ years (SD $11.41)$, current union $=8.66$ years $(S D 6.29)$, and current role $=5.17$ years $(S D 4.73)$. 
Approximately $47 \%$ of staff were 'administration' (including secretaries, communication officers, training officers, etc) and 53\% were 'officials' (organisers, industrial officers etc).

\section{Instruments}

Intentions to Leave (ITL) were measured using a three-item scale (Brough and Frame, 2004). An example item is 'How frequently have you seriously considered leaving your job in the past 12 months?' Respondents answered each item according to a 5-point Likert scale from $1=$ not at all to $5=a$ great deal. Cronbach alpha $(\alpha)$ was .84 . (All alphas reported are from the present study).

Intrinsic and Extrinsic Motivations were measured through combining multiple subscales, primarily from the Multidimensional Work Motivation Scale (MWMS: Gagné et al., 2015), which has been validated in seven languages. In light of recent studies incorporating unidimensional subscales rather than the entire MWMS (Olafsen et al., 2015), we used four of the six subscales. Each item reflects an answer to the question 'Why do you put effort into your current job?' along a seven-point scale from $1=$ not at all to $7=$ completely. Sample items include, 'To get others' approval - e.g., supervisor, colleagues, family, clients...' (from the external regulation-social subscale, $\alpha=.80$ ), 'Because others will reward me financially only if I put enough effort in my job' (external regulation-material; $\alpha$ $=.69$ ), 'Because putting effort in this job aligns with my personal values' (Intrinsicidentified regulation; $\alpha=.83$ ), and 'Because the work I do is interesting' (Intrinsic motivation-interest; $\alpha=.70)$. Two additional subscales were added to form the metascales. Intrinsic motivation - prosocial assessed the desire to expend effort to benefit other people, using a three-item scale developed by (Grant, 2008). Considering the high reliability coefficient derived from later versions of the scale (Benedetti, 2012), minor rephrasing was implemented to adapt to the union sector. Example item: 'Because I can make a positive 
impact on other individuals through this job' $(\alpha=.91)$. Extrinsic motivation-Advancement (Park and Word, 2012) measured the desire to expend effort for the sake of opportunities for career development $(\alpha=.88)$. An example item is 'Because of opportunity for advancement within the union'. The combined meta-scales used in this analysis incorporated the above three intrinsic and extrinsic drivers, with both full scales demonstrating high internal consistency - intrinsic motivations, $\alpha=.91$; extrinsic motivations, $\alpha=.82$.

Public service motivations (PSM) were measured with four items relating to public duty and self-sacrifice, as adapted by Stazyk (2013) from Perry's original scale (Perry, 1996). An example item is 'It is important for me to contribute to the common good'. Responses are recorded on a five-point scale from $1=$ strongly disagree to $5=$ strongly agree. We did not use the full scale in our analysis due to low variation in this high-PSM sample and since it had a low alpha, but we report frequencies for some items.

Fulfilled expectations were assessed through three items. These were measured on a five-point scale from 1 = strongly disagree to 5 = strongly agree, indicating the extent to which participants believed their employer had fulfilled its obligations to the employee regarding meaningful work and service to the membership. The items were adapted from a scale used in previous studies in the public service (Castaing, 2006). Example item includes 'Helping people in need'. Alpha $=.87$.

Training was adapted from an index of professional compromise, devised for health and human service research (Haynes et al., 1999). The two items were measured on a fivepoint scale from $1=$ not at all to $5=$ a great deal, with responses being 'Not having enough training to handle a situation' and 'Lack of clarity/agreement about the different responsibilities of different staff'. Other items from the professional compromise scale 
conceptually mapped onto factors relating to intra-personal role conflict, and as internal consistency of the full scale was low, each question was analysed individually against the dependent variables based on existing guidelines (Hayduk and Littvay, 2012). The question on training was used for the final analysis due to its higher correlations with key variables and its theoretical significance, and since it correlated highly with the number of training days employees had experienced over the previous 5 years. The focus in our training question is on the adequacy of training rather than the quantity of it, consistent with earlier research showing that outcomes among delegates in those unions were strongly related to the perceived adequacy, not the quantity, of organiser training (Peetz and Alexander, 2011).

Organisational support measured the union's performance as a fair and supportive employer, created upon request of the largest union involved. Given limitations in the instrument due to survey fatigue, this reflects our interest in a concise, composite indicator of how well employees believe staff are treated by the employer, both in terms of individual support and general fairness. Responses are recorded on a two-item, five-point scale from 1 = strongly disagree to 5 = strongly agree, regarding the statements 'In general, the union treats its employees fairly' and 'The union is effective in providing support to me in my job'. Alpha $=.84$.

Controls. A number of demographic control variables (age, education, gender) were initially included in correlations and regressions. However, as discussed later, these were found to have little explanatory power and so, in order to preserve adequate power, they were not included in the final equations. Low mobility in the labour market was included as a control variable and was measured by responses to the item 'I have too few options to consider leaving the organization' along a seven-point scale from $1=$ not at all to $7=$ 
completely. Burnout was also included as a control and was measured via two sub-factors of emotional exhaustion and cynicism (Roelen et al., 2015). The emotional exhaustion scale (Riley et al., 2018) contained three items as adapted from the MBI - HSS Maslach Burnout Inventory-Human Services Survey (Maslach et al., 1986). An example item was: 'Working with people all day is really a strain for me' (subscale $\alpha=.84$ ). The cynicism scale contained four items as adapted by Roelen et al. (2015) from the Maslach Burnout InventoryGeneral Survey (MBI-GS), and has good psychometric properties (Schaufeli et al., 2002). An example item is 'I have become more cynical about whether my work contributes anything' (subscale $\alpha=.86$ ). All items were measured on a 7-point scale, ranging from $0=$ never to $7=$ every day. Total burnout scale $\alpha=.91$.

We implemented several measures to reduce the impact of social desirability, although self-reports are still vulnerable to intentional and unintentional distortions (Geiger et al., 2018). Common method variance is a related problem, and we used several strategies to lessen this (Tehseen et al., 2017). We reduced socially-desirable responding and concerns regarding employer evaluation through: clear communication on the importance of accurate data; guarantee of anonymity; use of an external consultancy; strict ethical procedures; and allowing discretionary participation. We addressed potential issues with items by: using different measurement scales and anchor labels; counterbalancing and randomisation; psychologically separating variables through introductory statements; and pre-survey consultation with union leaders to ensure items were clear and well-defined while avoiding double-barrelled and complex wording. We used measures with demonstrated construct validity and internal consistency. We assessed the general convergence of quantitative results with (i) qualitative themes by conducting thematic analysis of open-ended questions at the end of the survey, and with (ii) existing knowledge 
of organisational climate through post-survey consultation with union leaders. We also deployed Harman's single factor test (Podsakoff, 2003) to conduct a factor analysis of all 12 variables via Principal Components Extraction. This yielded four factors with eigenvalue $>1$, accounting for $63 \%$ of the total variance. Since no single factor emerged, and as the primary factor only captured $30 \%$ of the variance, common method variance is unlikely to warrant major concern.

We undertook our analysis through frequency, bivariate correlation, and multivariate ordinary least squares (OLS) and moderated regression analysis. Results of the regressions are reported in Tables 2 and 3, with separate equations indicating steps in the regression analysis. We commence the results section with an overview of the public service motivations shown in the sample.

\section{Results}

This was a group characterised by high public service motivations. A major intrinsic motivation for union staff was to provide meaningful service to the membership, along with the broader community, with $96 \%$ and $95 \%$ of staff respectively agreeing that these were important. Three-quarters reported a willingness for self-sacrifice for a better community. With near unanimity on these PSM indicators, and only one of these three variables showing any correlation with ITL, we did not seek to model how PSM influenced ITL; rather, we had identified a sample characterised by high-PSM, and investigated how ITL was shaped in this high-PSM environment. 
Other intrinsic motivations were also evident. Employees stated that they put strong effort into their work for reasons of: person-job value alignment (89\%); ability to make a positive impact ( $85 \%)$; because the work is interesting $(81 \%)$ and fun $(55 \%)$; and because of opportunities for development (27\%). There was not as much importance placed on extrinsic motivations, with employees stating less frequently that they put strong effort into their work for reasons of: gaining respect (32\%); job security $(27 \%)$; career progression (16\%); organisational advancement (15\%); and financial reward (5\%). Employees rated their expectations being met or exceeded regarding: helping individuals (92\%), opportunity to do something worthwhile (92\%), and serving the broader community (89\%).

The mean score for ITL was low to moderate, with a minority of employees stating that they: had seriously considered leaving their organisation in the past 12 months (41\%), were likely to leave in the next 12 months (27\%), and were actively looking for alternative jobs (16\%).

\section{[INSERT TABLE 1 ABOUT HERE]}

The means, standard deviations and zero-order correlations are presented in Table 1. Unlike the other variables shown, gender, education and extrinsic motivations were not significantly correlated with ITL, and age quickly lost significance in regressions once other explanatory variables (including burnout and intrinsic motivations) were added.

We tested $H_{1}$ and $H_{2}$ through correlation and then regression analysis. The three primary sub-factors of intrinsic motivation were all significantly correlated with ITL (value alignment, $r=.29, p<.001$; interest-enjoyment, $r=.27, p<.01$; and pro-social motives, $r=$ 
$.26, p<.01)$, while the only extrinsic sub-factor that correlated significantly with ITL was job security $(r=.20, p<.05)$. However, these sub-factors, along with the meta-factors of extrinsic motivations (as shown through correlations in Table 1) and intrinsic motivations (as shown through regression equations 2.2 to 2.4 in Table 2) were not significantly associated with ITL after accounting for other factors. We therefore rejected $H_{1}$ and $H_{2}$. The four variables with the strongest associations with ITL in the correlation analyses organisational support, fulfillment of service expectations, burnout, and insufficient training - retained significance after accounting for other factors in the OLS regressions. As we demonstrate below, the key factor in explaining ITL was not whether motivations were intrinsic or extrinsic but whether the resultant expectations were met.

We used OLS regression equations in Table 2 to test $H_{3}, H_{4}$ and $H_{7}$, examining the main effect of burnout on ITL, the main effect of organisational support on ITL, and the moderation effect of insufficient training on the relationship between organisational support and ITL. Equation 2.1 shows that intrinsic motivation and low perceived mobility together explained about $16 \%$ of the variance in ITL. That is, ITL was lower where workers had higher intrinsic motivations and better perceptions of job mobility. However, equation 2.2 shows that these variables became non-significant (though their coefficients retained their signs) when burnout, a strong predictor of ITL, was added to the equation. High burnout was linked to high ITL, and the relationships between intrinsic motivations, low mobility and ITL were mostly explained by the role of burnout. (As shown in the Table 1 correlations, workers with high intrinsic motivation and high mobility were less likely to report burnout.) Thus workers with high intrinsic motivation or high mobility did not express burnout nor significant ITL. The independent role for burnout in predicting ITL supports $\mathrm{H}_{3}$. 
Equation 2.3 shows that insufficient training and organisational support both

predicted ITL, independent of the controls, with their inclusion explaining an additional $11 \%$ of variance in ITL. The independent roles for organisational support in predicting ITL supports $\mathrm{H}_{4}$.

Finally, in equation 2.4 we created a moderated regression by adding a term for the two-way interaction between insufficient training and organisational support in explaining ITL - in addition to the controls and main effects. Moderation effects and simple slopes were analysed using the 'PROCESS' plug-in for SPSS version 26 (Hayes, 2012), with the predictor variables mean-centred. This significantly improved the fit of the equation $\left(\Delta R^{2}=\right.$ $.02, \Delta F(1,143)=5.79, p=.017)$. Figure 2 illustrates the simple slopes analysis as plotted through the two-way linear interaction procedure from Hayes (2012). The results show that the presence of highly insufficient training $(+1 S D)$ significantly affected the relationship between organisational support and ITL, with the slope significantly different from zero $(b=$ $-.35, t(143)=-4.49, p<.001)$. The effect of sufficient training or 'low' insufficient training $(-1$ $S D)$, although weaker, was also significant $(b=-.15, t(143)=-1.99, \mathrm{p}=.049)$. That is, while ITL are adversely affected by inadequate training and low organisations support, the impact of low organisational support on ITL is much worse when employees perceive that their training is inadequate, thus supporting $H_{7}$.

\section{[INSERT TABLE 2 AND FIGURE 1 ABOUT HERE]}

We used the OLS regression equations in Table 3 to test $H_{5}, H_{6}$ and $H_{8}$, examining the main effect of unfulfilled service expectations on ITL, the main effect of insufficient training on ITL, and the moderation effect of insufficient training on the relationship between 
unfulfilled service expectations and ITL. Equations 3.1 and 3.2, representing the introduction of the control variables (mobility, intrinsic motivations and burnout), are the same as equations 2.1 and 2.2 in Table 2 and shown for simplicity of illustration.

Equation 3.3 shows that insufficient training and organisational support both predicted ITL, independent of the controls, with their inclusion explaining an additional $10 \%$ of variance in ITL. The independent roles for insufficient training and fulfilled service expectations in predicting ITL supports $H_{5}$ and $H_{6}$.

In equation 3.4, the two-way interaction between insufficient training and expectations was added to the controls and the main effects in explaining ITL. Notably, the $\mathrm{R}^{2}$ change for the addition of the interaction in the model was not significant. As illustrated by the similarity of the slopes in figure 2 , the relationship between expectations and ITL is independent from insufficient training. For this key explanatory variable - fulfilled expectations regarding meaningful service provision - training made little difference to its relationship with ITL. Therefore, $H_{8}$ was not supported. We created the two sets of equations, as shown in Tables 2 and 3, to demonstrate that while training has a significant impact on ITL, both as a main effect and in one interaction term, its moderating effects on variance in ITL do not apply across all contexts, but rather only in relation to some specific variables.

[INSERT TABLE 3 AND FIGURE 2 ABOUT HERE]

\section{Discussion}

One matter over which unions have direct control is the training provided to its employees, so can training reduce ITL? The results indicate that ITL was indeed directly 
predicted by the extent to which respondents thought that training enabled them to feel competent in handling a situation. In addition to facilitating training for competence, it is critical to employ preventative measures to reduce the incidence of emotional exhaustion and cynicism, given the strong influence of burnout on ITL. In addition, interventions to bolster employee perceptions of internal organisational fairness and support may offset the risk of ITL. If perceptions of low fairness and support remain, mobilizing skills training is likely to buffer any corresponding increase in ITL. By contrast, the presence of insufficient or sufficient training failed to change the impact of the fulfilled service expectations in explaining ITL. Respondents that perceived a breach of psychological contract regarding serving their members still reported significantly higher ITL compared to respondents reporting little or no breach, no matter their training.

These results suggest that training can make a difference to ITL both directly and indirectly by reducing the effect of other demotivating experiences. But it cannot do everything. The failure of a union environment to live up to key expectations of membership service cannot be overcome by training alone. A lack of training, poor support, unmet expectations and feeling burnt out all correlated strongly with ITL. While the extrinsic factor of job insecurity and all intrinsic drivers (value alignment, interestenjoyment, and prosocial motives) were significantly correlated with ITL, their effects became non-significant once other factors were added to the equation. Taken together, these results also support PEF theory, as maximising congruence between organisational values both internally (with staff) and externally (with members) appears critical in reducing ITL.

For several years Australian unions have been putting substantial resources into training and education of delegates, as critical to building power in the workplace. 
Attention must also be focused on the training and development of staff themselves. The findings demonstrate the importance of union education and training as part of a central strategy to retain good union employees. Other research into union delegates has shown the importance of both formal and informal dimensions of training, and of the follow-up to training courses (Peetz and Alexander, 2013). All of this would feed into the calculation of respondents' as to whether they had any misgivings about their training. Good training is not only important for helping union staff achieve the objectives of a union, it is also important for unions in retaining them. Indications from that earlier research into delegates that training can act as a moderator variable, enhancing the impact of prior activism on activism within a union, are shown to be relevant to union staff as well, but we must recognise that training's moderating effect does not apply to all issues, especially where the organisation has failed to live up to the expectations that it allowed new staff to have on joining the workforce for the union. No amount of training can stop dashed expectations from making employees think it is time to move on.

The reason why training moderates the effects of two factors on ITL quite differently probably lies in the divergent pathways they indicate for ITL. If people feel a lack of organisational support, they may feel they lack the resources to continue working for the union. Training provides personal resources that enable people to do their job well, potentially making up for those the union is otherwise inadequate at providing. If people feel their expectations have been unmet, however, the issue is not whether people have the resources to do a good job, it is whether it is even worthwhile doing. The employee who feels that the union no longer meets their expectations may well be thinking that they cannot make a positive difference in their present job, no matter how well they do it. Providing more resources through training will not alter that core problem. Training of 
delegates helps activism for the same reason that training union employees helps reduce ITL: it provides resources that enhance the skill base and sense of efficacy of the person being trained and enables them to think that they can make a difference. If the problem is not resources but purpose ('no matter how good a job I do, I cannot make a difference here'), the situation is very different.

\section{Theoretical Contributions}

To the authors' knowledge, this is the first quantitative study on a range of motivational drivers of union employees. This study responds to calls for more contextbased models (Ritz et al., 2016b), drawing on the individual profiles, organisational controls, and external conditions (Li et al., 2016) that influence withdrawal behaviours, in order to improve our understanding of complex interactions involving PSM, individuals, and work outcomes (Hom et al., 2019). This study also responds to an acknowledgement of the growing albeit still insufficient body of literature on the risky side of PSM (Christensen et al., 2017). This paper shows, for a group characterised by high PSM, how unfulfilled PSMrelated expectations and organisational support influence turnover intentions, and how these effects are in turn shaped by training. It reinforces the importance of facilitating person-role and person-organisation congruence, rather than simply selecting high-PSM employees, and shows the separate importance of resources and purpose and their links (or lack of link, in the latter case) to training.

\section{Practical Implications}

Human service organisations typically seek to attract quality candidates with a promise of meaningful work. However, an uninitiated entrant may lack the experience required to determine the level of emotional trauma they are likely to endure, especially if social support becomes scarce. Blunt discussions and role shadowing or paid job trials may 
help reduce premature future ITL through uncomfortable yet critical dialogues and on-thejob 'reality checks' that can help realign expectations to realities. Moreover, the more a union can do to match its own rhetoric, the more likely it is to retain capable employees.

\section{Limitations and future directions}

Some limitations of this study must be acknowledged. The use of cross-sectional data restricts the veracity of conclusions regarding causal effects. There are inherent difficulties in measuring largely unconscious processes. Intentional distortions such as 'faking good' may have influenced results, although these distortions are more prevalent in high stakes settings like job interviews (Geiger et al., 2018), and this study's guaranteed anonymity would reduce any effect. This sample was relatively small and from white collar unions in specific settings in Australia, thus limiting generalisability. To address these limitations, the authors are completing a follow-up, longitudinal study of a larger and more diverse sample of employees, both from within the union sector and across other fields within human services. As job security seems to be a key extrinsic driver in determining ITL, future iterations of motivational research on union staff and other human service employees could benefit from measuring the impact of Covid-19 on organisational commitment and intrinsic motivations.

\section{Conclusion}

Union employees in this sample have high PSM and are thus characterised by high intrinsic and prosocial motivations, with low extrinsic motivations aside from social approval and job security. If unions fail to meet the expectations of their staff, particularly relating to their ability to support members, those staff may leave - at considerable cost to the union. Union employees' heightened awareness of social and workplace justice, might make them more sensitive to imperfect work conditions and decision-making 
processes among other internal practices, but they will be especially sensitive to issues of purpose that no amount of training can address. For union leaders, then, a clear challenge is to align stated values with realities. Skills training can build personal resources and so dampen many of the frustrations staff have, given the effect of training on both employee competency and member impact. Professional development that enables organisation and career progression is likely to further boost commitment. Training can reduce the likelihood of burnout leading to turnover by building personal resources, but it cannot prevent staff from leaving if they see little purpose to staying because of dashed expectations.

\section{Declaration of conflicting interests}

The authors declared no potential conflicts of interest with respect to the research, authorship and/or publication of this article.

\section{Funding}

The authors received no financial support for the research, authorship and/or publication of this article. 


\section{References}

Allen DG, Bryant PC and Vardaman JM. (2010) Retaining talent: Replacing misconceptions with evidence-based strategies. Academy of management Perspectives 24: 48-64.

ANMF. (2019) Annual Report.

Bakker AB. (2015) A job demands-resources approach to public service motivation. Public Administration Review 75: 723-732.

Benedetti AA. (2012) Event-level intrinsic, extrinsic, and prosocial motivation: effects on well-being. University of Akron.

Brough P and Frame R. (2004) Predicting police job satisfaction and turnover intentions: The role of social support and police organisational variables. New Zealand Journal of Psychology 33: 8-18.

Bunderson JS and Thompson JA. (2009) The call of the wild: Zookeepers, callings, and the double-edged sword of deeply meaningful work. Administrative science quarterly 54: 32-57.

Burchielli R. (2004) "It's Not Just Numbers": Union Employees' Perceptions of Union Effectiveness. Journal of Industrial Relations 46: 337-344.

Burchielli R. (2008) Human resource management practices in trade unions: Implications for strategy. Asia Pacific Journal of Human Resources 46: 56-67.

Byrnes C and Lawn S. (2013) Disability Employment Services in Australia: A Brief Primer. The Australian Journal of Rehabilitation Counselling 19: 46-56.

Carter B and Cooper R. (2002) The organizing model and the management of change: A comparative study of unions in Australia and Britain. Relations Industrielles 57: 712742.

Castaing S. (2006) The effects of psychological contract fulfilment and public service motivation on organizational commitment in the French civil service. Public policy and administration 21: 84-98.

Chang WJA, Wang YS and Huang TC. (2013) Work design-related antecedents of turnover intention: A multilevel approach. Human Resource Management 52: 1-26.

Christensen RK, Paarlberg L and Perry JL. (2017) Public service motivation research: Lessons for practice. Public Administration Review 77: 529-542.

Clark PF and Gray LS. (2007) Administrative Practices in American Unions: A Longitudinal Study. Journal of Labor Research 29.

Coccia M. (2019) Intrinsic and extrinsic incentives to support motivation and performance of public organizations. Journal of Economics Bibliography 6: 20-29.

Conway N and Briner RB. (2005) Understanding psychological contracts at work: A critical evaluation of theory and research: Oxford University Press.

Cooper - Thomas HD and Wright S. (2013) Person - environment misfit: the neglected role of social context. Journal of Managerial Psychology.

Cooper R. (2003) Peak council organising at work: ACTU strategy 1994-2000. Labour and Industry 14: 1-15.

Crouch C. (2017) Membership density and trade union power. Transfer 23: 47-61.

De Cuyper N, Mauno S, Kinnunen U, et al. (2011) The role of job resources in the relation between perceived employability and turnover intention: A prospective two-sample study. Journal of Vocational Behavior 78: 253-263. 
Felps W, Mitchell TR and Byington E. (2006) How, when, and why bad apples spoil the barrel: Negative group members and dysfunctional groups. Research in organizational behavior 27: 175-222.

French JR, Caplan RD and Van Harrison R. (1982) The mechanisms of job stress and strain: Chichester [Sussex]; New York: J. Wiley.

Frey BS and Jegen R. (2001) Motivation crowding theory. Journal of economic surveys 15 : 589-611.

Gagné M, Forest J, Vansteenkiste M, et al. (2015) The Multidimensional Work Motivation Scale: Validation evidence in seven languages and nine countries. European Journal of Work and Organizational Psychology 24: 178-196.

Gahan P and Bell S. (1999) Union strategy, membership orientation and union effectiveness: An exploratory analysis. Labour \& Industry: a journal of the social and economic relations of work 9: 5-30.

Gall G and Fiorito J. (2014) Union effectiveness: In search of the Holy Grail. Economic and Industrial Democracy 37: 189-211.

Gall G and Fiorito J. (2016) Union effectiveness: In search of the Holy Grail. Economic and Industrial Democracy 37: 189-211.

Ganz ML, Voss K, Sharpe T, et al. (2001) Against the tide: Projects and pathways of the new generation of union leaders, 1984-2001.

Geiger M, Olderbak S, Sauter R, et al. (2018) The "g" in faking: Doublethink the validity of personality self-report measures for applicant selection. Frontiers in psychology 9: 2153.

Giauque D, Anderfuhren-Biget S and Varone F. (2013) Stress Perception in Public Organisations: Expanding the Job Demands-Job Resources Model by Including Public Service Motivation. Review of Public Personnel Administration 33: 58-83.

Giauque D, Ritz A, Varone F, et al. (2012) Resigned but Satisfied: The Negative Impact of Public Service Motivation and Red Tape on Work Satisfaction. Public Administration 90: 175-193.

Grant AM. (2008) Does intrinsic motivation fuel the prosocial fire? Motivational synergy in predicting persistence, performance, and productivity. Journal of Applied Psychology 93: 48.

Groothuizen JE, Callwood A and Gallagher A. (2018) What is the value of Values Based Recruitment for nurse education programmes? Journal of advanced nursing 74 : 1068-1077.

Haivas S, Hofmans J and Pepermans R. (2013) Volunteer engagement and intention to quit from a self - determination theory perspective. Journal of Applied Social Psychology 43: 1869-1880.

Hanisch KA. (2002) The timing of thinking about quitting. Voluntary employee withdrawal and inattendance. Springer, 193-211.

Hayduk LA and Littvay L. (2012) Should researchers use single indicators, best indicators, or multiple indicators in structural equation models? BMC medical research methodology 12: 159.

Hayes AF. (2012) PROCESS: A versatile computational tool for observed variable mediation, moderation, and conditional process modeling. University of Kansas, KS.

Haynes CE, Wall TD, Bolden RI, et al. (1999) Measures of perceived work characteristics for health services research: Test of a measurement model and normative data. British Journal of Health Psychology 4: 257-275. 
Hemdi MA and Nasurdin AM. (2006) Predicting turnover intentions of hotel employees: The influence of employee development human resource management practices and trust in organization. Gadjah Mada International Journal of Business 8: 21-42.

Hom PW, Allen DG and Griffeth RW. (2019) Employee Retention and Turnover: Why Employees Stay Or Leave: Routledge.

Jensen UT, Andersen LB and Holten A-L. (2019) Explaining a dark side: Public service motivation, presenteeism, and absenteeism. Review of Public Personnel Administration 39: 487-510.

Kang J-S. (2012) Psychological empowerment to the organizational commitment and turnover intention of social worker. International Journal of Contents 8: 88-94.

Kelly J and Heery E. (2009) Working for the union: British trade union officers: Cambridge University Press.

Kgapola LS. (2017) Trade unions service level and member satisfaction. University of Pretoria.

Kwon I. (2012) Motivation, Discretion, and Corruption. Journal of Public Administration Research and Theory 24: 765-794.

Lee YH. (2019) Emotional labor, teacher burnout, and turnover intention in high-school physical education teaching. European Physical Education Review 25: 236-253.

Li JJ, Lee TW, Mitchell TR, et al. (2016) The effects of proximal withdrawal states on job attitudes, job searching, intent to leave, and employee turnover. Journal of Applied Psychology 101: 1436.

Markey R and Simpkin G. (2017) Effectiveness of trade union workplace organisation: A case study of the new Zealand post primary Teachers' association. New Zealand Journal of Employment Relations 42: 52.

Martin R. (1999) Mobilization theory: A new paradigm for industrial relations? Human Relations 52: 1205-1216.

Maslach C, Jackson SE, Leiter MP, et al. (1986) Maslach burnout inventory: Consulting psychologists press Palo Alto, CA.

McAlevey J and Ostertag B. (2014) Raising expectations (and raising hell): My decade fighting for the labor movement: Verso Trade.

Milkman R and Voss K. (2004) Rebuilding labor: Organizing and organizers in the new union movement: Cornell University Press.

Morrow R and Brough P. (2019) 'It's off to work we go!'Person-environment fit and turnover intentions in managerial and administrative mining personnel. International Journal of Occupational Safety and Ergonomics 25: 467-475.

Moynihan DP and Pandey SK. (2008) The ties that bind: Social networks, personorganization value fit, and turnover intention. Journal of Public Administration Research and Theory 18: 205-227.

Muir K and Peetz D. (2010) Not Dead Yet: The Australian Union Movement and the Defeat of a Government. Social Movement Studies 9: 215-228.

Olafsen $\mathrm{AH}$, Halvari $\mathrm{H}$, Forest J, et al. (2015) Show them the money? The role of pay, managerial need support, and justice in a self-determination theory model of intrinsic work motivation. Scand J Psychol 56: 447-457.

Park SM and Word J. (2012) Driven to service: Intrinsic and extrinsic motivation for public and nonprofit managers. Public Personnel Management 41: 705-734. 
Patterson F, Prescott-Clements L, Zibarras L, et al. (2016) Recruiting for values in healthcare: a preliminary review of the evidence. Advances in Health Sciences Education 21: 859-881.

Peetz D and Alexander M. (2011) Sept thèses sur la formation syndicale: Propositions à partir d'enquêtes sur les lieux de travail en Australie. La Revue de I'IRES 68: 173-206.

Peetz D and Alexander M. (2013) A synthesis of research on training of union delegates. Industrial Relations Journal 44: 425-442.

Peetz D, Houghton C and Pocock B. (2005) Organisers' Roles Transformed? Australian Union Organizers and Changing Union Strategy. Journal of Industrial Relations 49: 151166.

Peetz D and Pocock B. (2007) Community activists, coalitions and unionism. In: Buttigieg D, Cockfield S, Cooney R, et al. (eds) Trade Unions in the Community: Values, Issues, Shared Interests and Alliances. Adelaide: Heidelberg books.

Perry JL. (1996) Measuring public service motivation: An assessment of construct reliability and validity. Journal of Public Administration Research and Theory 6: 5-22.

Perry JL and Wise LR. (1990) The motivational bases of public service. Public Administration Review: 367-373.

Podsakoff N. (2003) Common method biases in behavioral research: a critical review of the literature and recommended remedies. Journal of Applied Psychology 885: 10.1037.

Prouska R and Psychogios A. (2018) Do not say a word! Conceptualizing employee silence in a long-term crisis context. The International Journal of Human Resource Management 29: 885-914.

Riley MR, Mohr DC and Waddimba AC. (2018) The reliability and validity of three - item screening measures for burnout: Evidence from group - employed health care practitioners in upstate New York. Stress and Health 34: 187-193.

Ritz A, Brewer GA and Neumann O. (2016a) Public service motivation: A systematic literature review and outlook. Public Administration Review.

Ritz A, Brewer GA and Neumann O. (2016b) Public Service Motivation: A Systematic Literature Review and Outlook. Public Administration Review: n/a-n/a.

Roelen C, van Hoffen M, Groothoff J, et al. (2015) Can the Maslach Burnout Inventory and Utrecht Work Engagement Scale be used to screen for risk of long-term sickness absence? International archives of occupational and environmental health 88: 467475.

Schaufeli WB, Salanova M, González-Romá V, et al. (2002) The measurement of engagement and burnout: A two sample confirmatory factor analytic approach. Journal of Happiness studies 3: 71-92.

Schott C, Neumann O, Baertschi M, et al. (2019) Public Service Motivation, Prosocial Motivation and Altruism: Towards Disentanglement and Conceptual Clarity. International Journal of Public Administration 42: 1200-1211.

Siers B. (2007) Relationships among organisational justice perceptions, adjustment, and turnover of United States - based expatriates. Applied Psychology 56: 437-459.

Sonnentag S and Bayer U-V. (2005) Switching off mentally: predictors and consequences of psychological detachment from work during off-job time. Journal of occupational health psychology 10: 393.

Stazyk EC. (2013) Crowding out public service motivation? Comparing theoretical expectations with empirical findings on the influence of performance-related pay. Review of Public Personnel Administration 33: 252-274. 
Tangirala S and Ramanujam R. (2008) Employee silence on critical work issues: The cross level effects of procedural justice climate. Personnel Psychology 61: 37-68.

Tehseen S, Ramayah T and Sajilan S. (2017) Testing and controlling for common method variance: A review of available methods. Journal of Management Sciences 4: 142168.

Tett RP and Meyer JP. (1993) Job satisfaction, organizational commitment, turnover intention, and turnover: path analyses based on meta - analytic findings. Personnel Psychology 46: 259-293.

Thompson JA and Bunderson JS. (2003) Violations of principle: Ideological currency in the psychological contract. Academy of management review 28: 571-586.

Timms C, Brough P and Graham D. (2012) Burnt - out but engaged: the co - existence of psychological burnout and engagement. Journal of Educational Administration 50: 327-345.

Urbanaviciute I, Lazauskaite-Zabielske J, Vander Elst T, et al. (2018) Qualitative job insecurity and turnover intention. Career Development International.

van Loon NM, Vandenabeele W and Leisink P. (2015) On the bright and dark side of public service motivation: the relationship between PSM and employee wellbeing. Public Money \& Management 35: 349-356.

Vandenabeele W, Brewer GA and Ritz A. (2014) Past, Present, and Future of Public Service Motivation Research. Public Administration 92: 779-789.

VPSC. (2015) Making Flexible Work a Success.

Whitehead P, Clark PF and Gray LS. (2018) Adapting Union Administrative Practices to New Realities: Results of a Twenty-Year Longitudinal Study. 24: 155-184.

Yu K-H. (2018) Inclusive unionism: Strategies for retaining idealism in the Service Employees International Union. Journal of Industrial Relations 61: 33-56.

Zhao H, Wayne SJ, Glibkowski BC, et al. (2007) The impact of psychological contract breach on work - related outcomes: a meta - analysis. Personnel Psychology 60: 647-680. 


\section{MOTIVATION AND TURNOVER IN AUSTRALIAN UNION STAFF}

Table 1. Means, standard deviations, zero-order correlations and reliability coefficients for the independent, dependent, moderating, and control variables.

\begin{tabular}{|c|c|c|c|c|c|c|c|c|c|c|c|c|c|c|}
\hline & $\mathrm{M}$ & SD & 1 & 2 & 3 & 4 & 5 & 6 & 7 & 8 & 9 & 10 & 11 & 12 \\
\hline 1. Age & 45.31 & 11.51 & & & & & & & & & & & & \\
\hline $\begin{array}{l}\text { 2. Gender } \\
\text { (Female) }\end{array}$ & - & - & .16 & & & & & & & & & & & \\
\hline $\begin{array}{l}\text { 3. Education } \\
\text { (Post-graduate) }\end{array}$ & - & - & .10 & -.02 & & & & & & & & & & \\
\hline $\begin{array}{l}\text { 4. Intrinsic } \\
\text { motivations }\end{array}$ & 5.34 & 0.99 & $.22^{*}$ & -.01 & .03 & & & & & & & & & \\
\hline $\begin{array}{l}\text { 5. Extrinsic } \\
\text { motivations }\end{array}$ & 2.89 & 1.06 & $-.30 * *$ & -.04 & .06 & .10 & & & & & & & & \\
\hline $\begin{array}{l}\text { 6. Fulfilled } \\
\text { expectations }\end{array}$ & 3.26 & 0.64 & .16 & -.09 & .05 & $.39 * * *$ & .14 & & & & & & & \\
\hline 7. Training days & 12.19 & 12.65 & $.32 * *$ & $-.23^{*}$ & .19 & $.32 * *$ & -.08 & $.27^{* *}$ & & & & & & \\
\hline $\begin{array}{l}\text { 8. Insufficient } \\
\text { Training }\end{array}$ & 2.25 & 1.14 & -.13 & -.01 & -.08 & -.10 & -.01 & $-.17^{*}$ & -.18 & & & & & \\
\hline $\begin{array}{l}\text { 9. Organisational } \\
\text { Support }\end{array}$ & 3.64 & 1.14 & .04 & -.12 & .15 & $.36 * * *$ & .14 & $.33 * * *$ & .20 & $-.39 * *$ & & & & \\
\hline 10. Burnout & 2.97 & 1.45 & $-.30 * *$ & -.12 & -.02 & $-.41 * * *$ & .01 & $-.34 * * *$ & -.13 & $.40 * * *$ & $-.52 * * *$ & & & \\
\hline 11. Low Mobility & 2.37 & 1.69 & -.08 & .01 & -.08 & $-.40 * * *$ & $.27 * * *$ & -.12 & -.15 & -.17 & $-.31 * * *$ & $.41 * * *$ & & \\
\hline 12. ITL & 1.95 & 0.99 & $-.23^{*}$ & -.08 & -.06 & $-.32 * * *$ & -.05 & $-.43 * * *$ & $-.30 * *$ & $.42 * * *$ & $-.56 * * *$ & $.56 * * *$ & $.34 * * *$ & \\
\hline
\end{tabular}

${ }^{*} \mathrm{p}<0.05,{ }^{* *} \mathrm{p}<0.01,{ }^{* * *} \mathrm{p}<0.001$. Notes: $N=106-160$. 
Table 2. OLS regression analyses for predicting ITL, including training and organisational support

\begin{tabular}{|c|c|c|c|c|c|c|c|c|}
\hline \multirow[t]{2}{*}{ Equation no: } & \multicolumn{2}{|c|}{2.1} & \multicolumn{2}{|c|}{2.2} & \multicolumn{2}{|c|}{2.3} & \multicolumn{2}{|c|}{2.4} \\
\hline & $b$ & SE & $\mathrm{b}$ & SE & $b$ & SE & $b$ & SE \\
\hline Intrinsic Motivations & $-.23 * *$ & (.09) & -.09 & (.08) & -.09 & $(.08)$ & -.04 & $(.08)$ \\
\hline Low Mobility & $.16^{* *}$ & $(.05)$ & .07 & $(.05)$ & .07 & (.05) & .05 & $(.04)$ \\
\hline Burnout & & & $.33 * * *$ & $(.05)$ & $.19 * * *$ & $(.06)$ & $.19 * *$ & (.06) \\
\hline Insufficient training & & & & & $.15^{*}$ & $(.06)$ & $.13^{*}$ & (.06) \\
\hline Organisational support & & & & & $-.27 * * *$ & (.07) & $-.25 * * *$ & $(.06)$ \\
\hline $\begin{array}{l}\text { Insufficient training } \times \\
\text { Organisational support }\end{array}$ & & & & & & & $-.09 *$ & (.03) \\
\hline Total $R^{2}$ & $.16^{* * *}$ & & $.33 * * *$ & & $.44 * * *$ & & $.46^{* * *}$ & \\
\hline Adjusted $\mathrm{R}^{2}$ & $.15^{* * *}$ & & $.32 * * *$ & & $.42 * * *$ & & $.44 * * *$ & \\
\hline $\mathrm{R}^{2}$ change & $.16^{* * *}$ & & $.17^{* * *}$ & & $.11 * * *$ & & $.02 *$ & \\
\hline $\mathrm{F}$ & $13.84^{* * *}$ & & $23.86 * * *$ & & $22.77^{* * *}$ & & $5.79 * * *$ & \\
\hline
\end{tabular}

Notes: $N=149 . \mathrm{b}=$ unstandardized regression coefficient; $\mathrm{SE}=$ standard error of $\mathrm{b}$. 


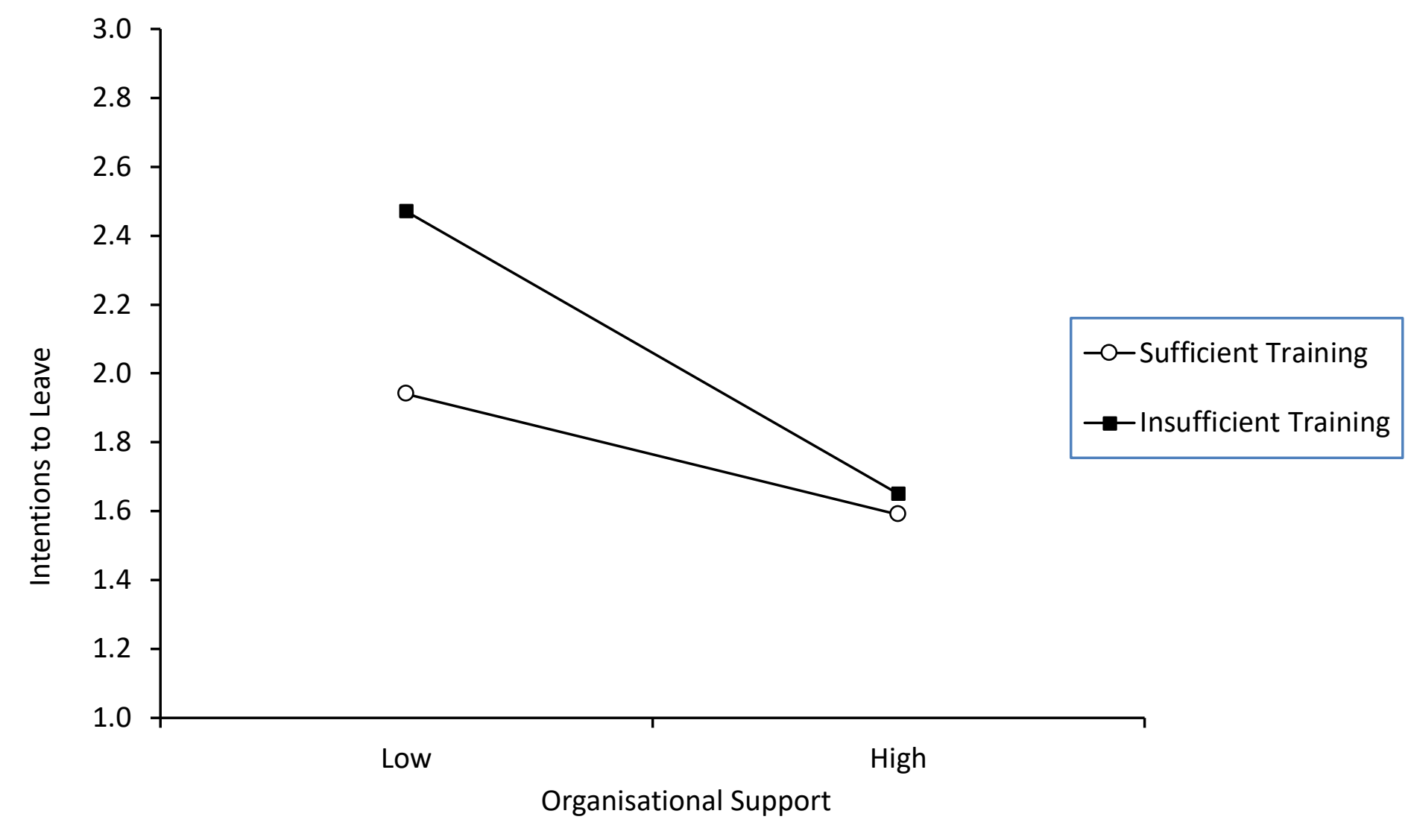

Figure 1. Simple slopes for the relationship between ITL and organisational support as moderated by insufficient training, with intrinsic motivations, low mobility, and burnout as the controls.

Note: Value labels 'Sufficient training' and 'Insufficient training' refer to one standard deviation above and below the mean. 


\section{MOTIVATION AND TURNOVER IN AUSTRALIAN UNION STAFF}

Table 3. OLS regression analyses for predicting ITL, including training and fulfilled expectations

\begin{tabular}{|c|c|c|c|c|c|c|c|c|}
\hline \multirow[t]{2}{*}{ Equation no: } & \multicolumn{2}{|c|}{3.1} & \multicolumn{2}{|c|}{3.2} & \multicolumn{2}{|c|}{3.3} & \multicolumn{2}{|c|}{3.4} \\
\hline & $\mathrm{b}$ & SE & $\mathrm{b}$ & SE & $\mathrm{b}$ & SE & $\mathrm{b}$ & SE \\
\hline Intrinsic Motivations & $-.23 * *$ & (.09) & -.09 & $(.08)$ & -.01 & $(.08)$ & -.02 & $(.08)$ \\
\hline Low Mobility & $.16^{* *}$ & $(05)$ & .07 & $(.05)$ & .08 & $(.05)$ & .08 & $(.04)$ \\
\hline Burnout & & & $.33 * * *$ & $(.05)$ & $.22 * * *$ & $(.06)$ & $.22 * * *$ & $(.05)$ \\
\hline Insufficient training & & & & & $.20 * *$ & $(.06)$ & $.19 * *$ & $(.06)$ \\
\hline Fulfilled expectations & & & & & $-.40 * *$ & $(.11)$ & $-.37 * *$ & (.11) \\
\hline $\begin{array}{l}\text { Insufficient training } \times \\
\text { Fulfilled expectations }\end{array}$ & & & & & & & -.06 & $(.05)$ \\
\hline Total $R^{2}$ & .16 & & .33 & & .43 & & .43 & \\
\hline Adjusted $R^{2}$ & .15 & & .32 & & .41 & & .41 & \\
\hline $\mathrm{R}^{2}$ change & $.16^{* * *}$ & & $.17^{* * *}$ & & $.10^{* * *}$ & & $<.01$ & \\
\hline $\mathrm{F}$ & 13.84 & & 23.86 & & 21.52 & & 1.3 & \\
\hline
\end{tabular}

Notes: $N=149 . \mathrm{b}=$ unstandardized regression coefficient; $\mathrm{SE}=$ standard error of $\mathrm{b}$. 


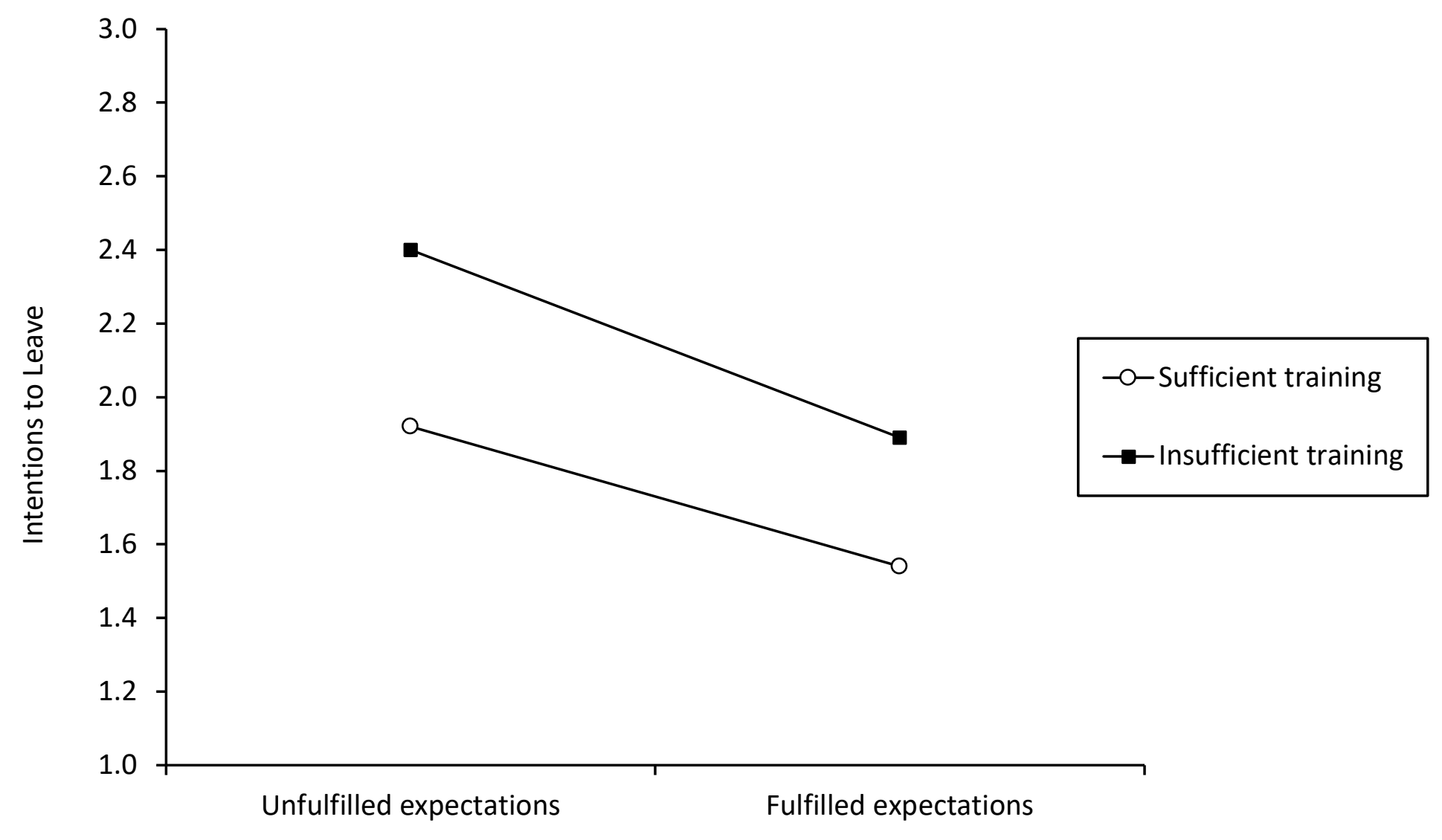

Member service expectations

Figure 2. Simple slopes for the relationship between ITL and fulfilled service expectations, as moderated by insufficient training, with intrinsic motivations, low mobility, and burnout as the controls.

Note: Value labels 'Sufficient training' and 'Insufficient training' refer to one standard deviation above and below the mean. 